\title{
Unpacking the Mechanisms Shaping Perceptions of Quality in Early Childhood Education Research and Practice as Illuminated by Cross- Cultural Conversations Between Practitioners from Britain and Jamaica
}

\author{
Zoyah Kinkead-Clark and Charlotte Hardacre
}

\begin{abstract}
Zoyah Kinkead-Clark is a senior lecturer, researcher, and coordinator of early childhood programs at The University of the West Indies, Mona, Jamaica. As a researcher, she is particularly interested in understanding how young children are shaped by their ecological experiences within the home and wider community with the view to explore how educators can build on these experiences in early years classrooms. Email: zoyah.kinkeadclark02@uwimona.edu.jm

Charlotte Hardacre is a lecturer in the Department of Health, Psychology, and Social Science at the University of Cumbria, where she has been a faculty member since 2014. She teaches a range of undergraduate modules in the Working with Children and Families degree program, with a focus on early childhood education and intergenerational learning.
\end{abstract}

Through cross-cultural conversations between teacher educators from Jamaica and the UK, this paper explores the drivers of how quality ECD is perceived. Our dialogue is grounded in our positional contexts: one from a context that reflects the Eurocentric model of "bestpractice" and one that measures itself against it. Using thematic analysis, we highlight three overlapping drivers that shape how quality is perceived. Our findings eschew the perception that quality is represented in one way. We point to dangers of homogenistic beliefs. We suggest that deficit approaches to local contexts obscure local knowledge and sociocultural factors.

Key words: knowledge democracy; Jamaica; UK; quality; early childhood; cross-cultural discourse
Globally, attempts to develop standards and improve educational outcomes have largely been the impetus behind early childhood education (ECE) reform efforts. Notwithstanding the difficulty in achieving these objectives, decisions driving such efforts have predominantly revolved around providing "quality" and have responded to questions surrounding "What can we do better?", "What does it look like?" and "What do we do next?" These questions are important for both researchers and practitioners because, as Michele Schweisfurth (2014) notes, the global quality imperative has often been "addressed obliquely and couched in terms of its outcomes rather than its processes" (p. 260), shifting the focus of research toward evidence-based practice that uses cause and effect models and quantitative impact measurement (National Institute for Health and Care Excellence, 2014; Nesta, 2018; Stewart-Brown et al., 2011).

Jamaica and Britain are two countries that have asked such questions about quality in ECE and which are admittedly at different points in articulating a response

to them. For instance, in Jamaica, it is quite clear that the early childhood sector stands at a unique point in its bid to provide quality services for children in the early years (Kinkead-Clark, 2015). Increasing investments in the sector have resulted in greater student enrollment in early years institutions, improved teacher qualifications, and the implementation of standards to improve the quality of offerings to children from birth through 5 years.

Likewise, in the UK, focus on ECE as the "great equalizer" has been the impetus behind decisions to ensure equity and equality in access to ECE offerings across the country (Dua et al., 2016). Because of the reciprocal relationship between research and practice, policy shifts by the authors' respective governments have been directly informed by current research guiding ECE. This has led to the British government's pronouncement that all 3- and 4-yearold children have a statutory right to ECE. As a result, decisions have been made to provide free child care for all 2-year-olds and to subsidize 30 hours of child care for 3- and 4-year-olds (Pascal et al., 2013). 
It is abundantly clear that in both Jamaica and the UK, while decisions driving ECE sector development have largely been in response to societal needs, the overarching goals to improve ECE offerings have had both positive and negative ramifications. In the UK, for instance, the decision to promote equity in access to affordable and high-quality care has overwhelmingly been in response to the political and social climate seeking to increase access to preprimary schooling, yet in ways that do not disrupt austerity measures (West, Roberts, \& Noden, 2010). Coupled with this response, "audit agendas" have also funnelled their way into the mix, driving literacy and numeracy requirements with the goal of putting British children on par with their Finnish counterparts (Lewis \& West, 2016; Lloyd, 2015). Similarly, in Jamaica, a significant factor that has led to much of the change in the ECE sector has been the development of policies in support of sector reform fuelled by Jamaica's goal to achieve developed country status by the year 2030. Interestingly, Jamaica too is dogged by the challenge of how to claim a greater stake in ECE but in ways that do not directly impact the meagre coffers of the government.

Though well intentioned, the undercurrents driving sector development in both Britain and Jamaica have also had uneven effects. For instance, "big policy" initiatives, including the UN's sustainable development goals and Jamaica's national development plan Vision 2030, have triggered a range of "little policy" activities in a ripple effect of intended and unintended consequences. In the UK, the frequent comparisons to the Finnish model of education have amplified messages to British teachers of the perceived inferiority of their practices and have resulted in highly stressful learning environments, especially when one considers the proposed "testing" of children in reception classrooms (Beliner, 2018).

Using cross-cultural conversations between two researchers who are also early childhood educators, one from Jamaica and one from the UK (see Table 1 for a comparative look at ECE in Jamaica and the UK), this paper explores what informs perceptions of quality in early childhood education and care. This dialogue is informed by our experiences as both practitioners and researchers. Our dialogue is also grounded in our positional contexts: one from a context that reflects the Eurocentric model of "best-practice" and the other from a context which frequently measures itself against these Eurocentric models, which are positioned as the gold standard for developing nations (Rao et al., 2014).

\section{Research aims}

This study has three aims. It first examines how research contexts guide researchers' assumptions about quality and how it is constructed. Second, we examine the dangers of "knowledge capitalism," a practice that has largely positioned knowledge construction in the hands of countries from dominant-hegemonic perspectives. Finally, through a prominence/perception matrix, we propose a framework for how researchers and other stakeholders can challenge such practices by accepting the need to destabilize commonly assumed "positions of power" and by adopting an awareness of the importance and value of knowledge democracy (Hall, 2014). 


\section{Research context}

Table 1 below briefly describes the research context by comparing Jamaica and the UK on a number of factors.

Table 1: Comparative Look at the ECE Contexts of Jamaica and the UK

\begin{tabular}{|c|c|}
\hline Jamaica & The UK \\
\hline Developing country & Developed country \\
\hline Lower- to middle-income state & Economically advanced \\
\hline Formal early childhood curriculum & Formal early childhood curriculum \\
\hline No standard early childhood policy exists & Established early childhood policy in place \\
\hline $\begin{array}{l}\text { Educational standards largely driven by } \\
\text { the goal of meeting developed country } \\
\text { status by } 2030\end{array}$ & $\begin{array}{l}\text { Educational standards largely driven by the desire } \\
\text { to have a system on par with Finland }\end{array}$ \\
\hline $\begin{array}{l}\text { Majority of ECE centres are privately } \\
\text { funded, though the government is seeking } \\
\text { to increase involvement in ECE }\end{array}$ & $\begin{array}{l}\text { Government minimally involved in ECE with } \\
\text { ahands-off approach predominantly taken, though } \\
\text { evidence suggests this will soon change }\end{array}$ \\
\hline ECE evolving from its grassroots legacy & Formally developed ECE system \\
\hline $\begin{array}{l}\text { Explicitly stated minimal educational } \\
\text { qualifications for practitioners }\end{array}$ & $\begin{array}{l}\text { Explicitly stated minimal educational qualifications } \\
\text { for practitioners }\end{array}$ \\
\hline $\begin{array}{l}\text { Over } 95 \% \text { of } 3 \text { - to } 5 \text {-year-olds enrolled in } \\
\text { preprimary school }\end{array}$ & $\begin{array}{l}\text { Over } 95 \% \text { of } 3 \text { - to } 5 \text {-year-olds enrolled in } \\
\text { preprimary school }\end{array}$ \\
\hline
\end{tabular}

ECE a national priority

ECE a national priority

\section{Literature review}

In working to understand how the different research contexts we operate in have shaped our assumptions about quality practice in early childhood education, we were first enlightened by studies that describe how research is perceived and ordered in the world, notably through Budd Hall's (2014) and Rajesh Tandon's (2014) work on knowledge democracy. This led us to engage with scholarship that considers the ways research hierarchies can be subverted. Here, as researchers from previously colonized and colonizing countries respectively, we found Tula Brannelly's (2016) and Gabrielle Russell-Mundine's (2012) work on decolonizing research useful. Finally, because of the cross-cultural nature of our research, we were also led by Morton Beiser (2003), Brigit van Widenfelt and colleagues (2005), and Sullivan and Cottone (2010). These scholars have helped us to conceptualize the ways in which research can be socially and culturally situated and the importance of finding ways to reveal and navigate normative or deficit framings of early childhood education practice in research. 


\section{Unpacking knowledge democracy: Who "owns" knowledge construction?}

Hall (2014) articulates knowledge democracy as an "opening outwards of comfortable assumptions about whose knowledge counts, and how life and knowledge are related to each other" (para. 7). This definition challenges narrow views of what legitimate research can be and the constricted spaces in which legitimate knowledge production can take place. This more open definition is instructive for researchers seeking to engage with, and contribute to, the knowledge base for quality ECE research, as it calls for critical evaluation of the suppositional barriers which may enclose or exclude rightful knowledge (Mullett, Openjuru, \& Jaitli, 2015). Much of the literature on knowledge democracy focuses on capturing and mobilizing grassroots knowledge within communities in order to build local capacity to meet socially just aims (Gaventa \& Cornwall, 2008; Hall, Jackson, \& Tandon, 2013; Tremblay \& de Oliveira Jayme, 2015). This movement has been part of dismantling the "research monopoly" of the academy because, as Gert Biesta (2011) points out, "nowadays research is carried out in many places outside the university" (p. 46).

Despite rising pluralism in research, there has not been a neutral shift whereby knowledge production has transferred from the hands of elite institutions to the hands of "the people." Rather, alongside a growing participatory research movement there has also been an increase in the commodification of knowledge, "with business, media, think tanks and civil society challenging the traditional hegemony of universities as the only recognized sites of knowledge production" (Tandon, 2014, p. 2). Illuminating this point, Biesta (2007) notes that while the university may no longer hold the monopoly on research, it may maintain a "knowledge monopoly" through its power to anoint small-scale community-driven research with legitimacy through publication and partnership activities. It is in relation to this power dynamic that George Openjuru and his colleagues (2015) call for broader definitions of knowledge to be affirmed "within the framework of the current mainstream academic and knowledge publication/ sharing systems outside participatory research or community circles" (p. 221). This cautionary note is a reminder that certain types of knowledge have gained acceptance only in certain spaces, creating a fragmented and shifting landscape of recognized knowledge that is dependent not only on who creates but also on who reads, shares, and applies knowledge.

\section{Accepting plural voices in knowledge construction}

Inadvertently, straightforward conceptions of knowledge democracy may valorize plurality but minimize how the competing voices that emerge are inequitably positioned due to uneven distributions of power. Kaz Stuart and Marnee Shay (2018) suggest that this inequity, and associated "epistemological exclusion," emanates from the preeminent positioning of impact measurements and scientific approaches to data collection and analysis. This perspective is frequently advanced by a dominant neoliberal agenda in global education research and policy making (Schweisfurth, 2014). This imbalance could potentially be revealed by delineating how the various producers of knowledge, such as academic institutions, think tanks, and intergovernmental organizations, engage with local communities in practice.

Further compounding this situation is the obfuscating effect of a tokenistic coopting of the language of participatory researchacross much commissioned and academicresearch(Rutkowski,2007). DanielSarna-Wojcickiand colleagues (2017) neatly articulated this concern in their study examining the "unnamed" contributors in participatory research. It is also evident in the rhetoric of mission statements and briefing documents of intergovernmental organizations that emphasize the importance of cocreating knowledge and participatory approaches in developing education policy (Fredericks, 2009; Lingard; 2013; Rutkowski, 2007; Tremblay \& de Oliveira Jayme, 2015) but are not always transparent about the nature, depth, and challenges of such collaborations. 
An increasing number of scholars characterize this shift toward a democratic rhetoric around knowledge production in education as part of a global system of neoliberalism that privileges education's economic role in relation to the creation of human capital (Apple, 2000; Russell-Mundine, 2012; Rutkowski, 2007; Stuart \& Shay, 2018). This reading suggests that the hollow incorporation of participatory and collaborative terminology, particularly into commissioned research, is part of a meritocratic discourse that emphasizes local people's self-determination and their right to be heard but does not necessarily account for the factors that marginalized their voices in the first place. Quentin Wheeler-Bell (2017) adds texture to this concern by noting that while including grass-roots perspectives in the production of knowledge should not be tokenistic or inauthentic, equally researchers should beware assuming marginalized communities automatically and unproblematically provide the best or purest forms of knowledge. Thus, gathering knowledge democratically "entails more than including the least advantaged into the deliberative process ... Respecting individuals, in this sense, requires subjecting both one's own opinions as well as those who are oppressed to reasonable arguments" (Wheeler-Bell, 2017, p. 574).

\section{Interrogating hierarchical agendas in knowledge production}

There are many concerns for researchers who are presented with global priorities that are dissonant from the local realities in which they operate. These concerns serve as an impetus for disentangling ideas about quality from politicized versions of best practice (Alexander, 2015; Boyd, 2009). This need to interrogate hierarchical agendas in knowledge production resonates with the work of Levermore and Beacom (2009, as cited in Mwaanga \& Adeosun, 2017), who point to "vertical partnerships" in which "northern experts speak on behalf of the south" (pp. 5859). This phenomenon, Richard Giulianotti (2004, p. 22) suggests, is the "cultural legacy of colonialism" wherein, as Brannelly (2016) argues, the presumption of expertise is analogous with the assumption of a "dominant and colonising position ... which fails to recognise the expertise and worldview of colonised societies” (p. 4).

This position is in line with Stuart and Shay (2018), who draw on Linda Tuhiwai Smith (2012) and Aileen Moreton-Robinson (2009) to note that "Western knowledges continue to dominate the epistemic realm of knowledge production, emphasising white, patriarchal imperialism, while Indigenous knowledge continues to be positioned as a paradigm on the peripheral" (p. 7). As well as marginalizing local voices, neocolonial approaches to knowledge also have a homogenizing effect. This, according to Douglas Hartmann and Christina Kwauk (2011), can be observed in the way singular solutions, such as sporting, entrepreneurial, or intergenerational programs, are applied to diverse problems. Oscar Mwaanga and Kola Adeosun (2017) suggest that the development of broadstroke, panacea solutions is "perpetuated by inter-governmental organisations and corporations who embody the belief that inhabitants of the global south share the same identity and henceforth share the same problems that require the same solutions" (p. 59).

\section{Methodology}

This study forms part of a larger body of research. As two researchers from different research contexts, we engaged in a series of cross-cultural conversations to discuss critical issues germane to early childhood education and care in our respective countries. In this piece, once again using cross-cultural conversations, we discussed the underlying issues which reflect notions of how quality is construed in Jamaica and the UK.

As Riitta Suhonen and colleagues (2009) suggest, cross-cultural research provides a robust opportunity to advance knowledge by taking a global perspective on critical issues. Likewise, as Oluwatoyin Ilesanmi (2009) proposes, cross-cultural research ultimately seeks to remove barriers and bias in research by acknowledging cultural differences while simultaneously reaffirming global similarities. 
Cross-cultural approaches are a useful response to ethnocentric discourses on knowledge production (Beiser, 2003; Sullivan \& Cottone, 2010) because of their potential to contextualize researcher interpretations and situate knowledge within local communities. This possibility is demonstrated in a study by van Widenfelt et al. (2005) which found that ethnocentric definitions of "social competence" for children resulted in bias and inaccurate conclusions because of the differing, culturally situated meanings attached to the term. This finding indicates one way in which a cross-cultural approach may help researchers "to reconsider conceptualizations that appear to be universal yet are actually based in Western standards and perspectives" (Sullivan \& Cottone, 2010, p. 360). As two researchers who sought to do just this, we engaged in a series of conversations to understand how our individual research studies in our own research contexts compared to each other. Having the opportunity to engage in this critical discourse enabled us to challenge much of the rhetoric, biases, and assumptions of how, why, and what fuels perceptions of quality.

\section{Data collection}

The data for this research was garnered over 11 and a half hours of conversations unevenly distributed over five meetings via Skype. Each conversation followed a pattern, which helped us to manage the copious information gathered throughout our discussions. Because we understood lack of focus as one of the dangers that might potentially emerge while we engaged in our discussion, prior to commencing each conversation, we outlined an unofficial agenda to detail what we wanted to discuss in the session. In addition to helping to minimize the frequency of straying too far off on tangents, it also helped us to ensure that we were "productive" in each conversation by ensuring we addressed key issues relevant to our contexts (Hartung \& Wilson, 2016).

Throughout each conversation, both of us took note of comments, questions, and remarks which we individually thought were particularly important to the discussion and the general focus of the research. We found that note taking, rather than recording each conversation, was especially useful. Rather than detract from the fluidity of our discussions, note taking served a powerful role in that it really helped us to focus on key points we thought were significant to our own research contexts. Thus, our conversations had the potential to be a purposeful yet intuitive exploration of our extant positions in a dialogue enhanced by "immediacy, personal relevance, rich stories, serendipity, improvisation, an open agenda, permissiveness, and risk-taking” (Haigh, 2006, p. 14), all of which are distinct elements of conversation which may be found less often in other data collection methods, such as structured interviews or oral surveys.

Each conversation ended with each of us summarizing the keys points of our discussion as we saw it. This practice served two purposes. First, it helped us to clarify issues that we felt needed to be further explored or explained, and second, it provided a springboard for us to highlight unofficial themes which we felt emerged from each conversation.

\section{Data analysis}

The data for this research was analyzed thematically (Braun \& Clarke, 2006; Nowell et al., 2017). To do this, we individually coded the data we had collected over the conversations. This information was placed in broad categories based on similarities and differences in meaning. The second phase, axial coding, involved reexamining the previously coded information to determine if the information accurately reflected our discussions. In this phase, categories were also reordered and merged based on a process of "revisiting, de-familiarizing, and alternative casing" (Timmermans \& Tavory, 2012, p. 180). In the third phase, the data was once again recoded, merged, and recoded again. This was done until saturation was reached and inherent themes were extracted. 
After analyzing the data to determine the themes, we shared them with each other. We were able to look at each other's suggestions and discuss the similarities in themes we felt emerged from the data. Our discussion led us to propose three broad drivers for understanding quality in early childhood education and care: framing, saming, and shaming.

\section{Findings}

Our cross-cultural conversations revealed three drivers that shape our understanding of how quality is perceived in early childhood education and care. These drivers are summarized in Table 2 and then explored in more detail below.

Table 2: Drivers Shaping Our Understanding of How Quality is Perceived

Driver Overview

\begin{tabular}{ll}
\hline Framing & $\begin{array}{l}\text { The relational framework we use to consider what quality means. Involves framing } \\
\text { our research and practice in relation to that of another country. }\end{array}$ \\
\hline Saming & $\begin{array}{l}\text { The perception that all developed or developing countries have the same sets of } \\
\text { strengths and weaknesses. }\end{array}$ \\
\hline Shaming & $\begin{array}{l}\text { The impact of relegating research from/about developing countries to the margins } \\
\text { of research about quality in ECE. }\end{array}$
\end{tabular}

Framing

Within our conversations, we frequently articulated our understanding of quality through comparisons with other countries, particularly those widely regarded as exemplars of best practice in ECE, such as Finland and Denmark. At first, framing our research in this way was a helpful explanatory tool, bounding our discussions and providing benchmarks for what we perceived as effective approaches, such as child-centered play or outdoor learning. However, this relational framework quickly became constrictive, with Charlotte noting that in ECE

we are always trying to get to a mythical land of best practice, and by focusing on that we spend more time gazing at a horizon we never reach, rather than focusing on our own settings.

We both expressed, with frustration, a feeling that our research and practice contexts were being positioned at differing points on a continuum, moving from poor to better to best. We found this particularly concerning because shifting global priorities, investment patterns, and educational trends ensure that notions of quality are in continual flux, and thus the continuum is a shape-shifting entity that cannot be traversed in a straightforward manner. There was also an uneasy sense in our discussion of being relational to one another hierarchically, with Charlotte's practice and research taking place in a developed nation and Zoyah's taking place in a developing nation. This did not fit with our personal perceptions of our own or each other's practice. Thus, simplistic notions that practice in developed nations is "better" than that in developing nations were easy to dismiss as ill-fitting and inaccurate, but we both recognized that deficit narratives are resistant to dismissal in the wider field. Zoyah shared: 
I submitted an article to an international ECE journal and was informed it would not be "of interest to an international audience" whilst a paper from Sweden (focusing on a similar topic) was included in the edition. My experience is that perspectives from developing nations are often positioned as of marginal interest because they don't fit with ideas about gold-standard or best practice.

We noted that country-level discussions enable glib comparisons to emerge, such as suggesting that ECE in one nation would benefit from a shift in practice to become "more like" the ECE of another nation. These types of broad-stroke analysis lacked relevance and utility at our person-to-person-level discussion. However, a feeling of disempowerment remained because framing was experienced as something that happens to researchers and necessitates time-consuming deconstruction before each researcher could share their work with the field.

Saming

Alongside our experiences around the framing of research, we identified an interrelated driver of conceptions of quality in ECE, which we came to refer to as saming (this is distinct from the term othering, which connotes a marginalizing form of difference). Our initial discussions about this phenomenon related to the subordinate treatment of research emerging from the developing world, and we described this in line with the concept of othering as a reductive label for people who do not fit in with dominant societal norms. This was evident in our conversations when Charlotte shared:

It would be unusual to look to Jamaica or other developing nations as a place to find aspirational practice-like you might with Reggio Emilia or Denmark. Usually, developing nations are seen as niche or special interest only. I feel there's a sense of exoticism and a fascination with cultural features such as food, music, and festivals but less interest in the intellectual offerings of those countries.

However, our analysis of the conversations led us to shift our attribution from one of othering to one of saming. This concept is in line with Naomi Schor's (1995, p. 51) discussion of Irigaray's feminist thinking, which contends that while othering acknowledges the notable difference within an individual, saming denies the "objectified other the right to her difference" and thus the specificity that is essential when describing the nature of a person or place is eliminated.

This process of saming was evident in our dissatisfaction with the homogenous treatment of groups of nations and their approaches to early childhood education and care. The perception that all developed or developing countries have the same sets of strengths and weaknesses was an unhelpful and persistent facet of our discussion that we often associated with the global priorities operating in our contexts. Charlotte articulated this in relation to the impact of the Organisation for Economic Cooperation and Development's (OECD) Programme for International Student Assessment (PISA) in the UK, saying:

We are continually made aware of where we sit in the PISA rankings, and the need to improve our position is a real driver for making young children in England "school ready."

Zoyah was similarly attuned to the influence of the Vision 2030 agenda on a range of associated early childhood policies in Jamaica. Both participant-researchers found global priorities limiting and reductive to work with because they remove context and overlook diversity. Our conversations revealed that our differing contexts did not protect us from either the requirement to meet a common standard or the expectation that one-size-fits-all measures would work to support these endeavours. 


\section{Shaming}

As we further analyzed our data, the mechanism of shaming was revealed in our experiences of how quality is expressed in early childhood and care. This driver was challenging to confront and we often referred to it obliquely until we established a sufficiently open dialogue. While we had established that dominant hegemonic structures enable a more prolific research output from developed nations, often minimizing or excluding the voices of developing nations, our analysis uncovered two factors in relation to shame. First, it means that researchers from nondominant contexts are relegated to trawling through swaths of research that are only tangentially related to their context. This is a disheartening and disempowering process that engenders a sense of being excluded from the narrative, which Zoyah alluded to when she noted:

I really have to work with what best fits or what I can make work when it comes to engaging with literature on children's play, for example, because the idea that children are not playing outdoors anymore is a common thread but is not relevant to the Jamaican context.

Zoyah noted that this challenge had not prevented her from pursuing her own research or attending international conferences to disseminate her work, but she was aware that colleagues had at times internalized the perception that dominant hegemonic perspectives were the gold standard, leading them to privilege textbooks or visiting speakers from these countries over local authors and speakers.

The second feature of shaming we identified was the resonance this process of documenting and disseminating narratives about quality has with marginalizing and exclusionary neocolonial attitudes and values. Charlotte found these overtones uncomfortable, whereas Zoyah noted that recognizing and articulating such concerns was a regular part of her academic life. Charlotte explained:

I find it a difficult subject to broach as I am so conscious that it may not be my story to tell or that I might articulate it inaccurately or in a patronizing way. Which is strange as the UK context is multicultural, and so not only do I want to engage with a wider range of voices, surely it's an obligation if I want to get a proper sense of the varied communities I conduct research within.

Thus, shaming relates to the sense of shame researchers might feel when they are excluded from the narrative, to the sense of shame that is internalized about knowledge produced by local people, and also to the sense of shame researchers feel about being part of a marginalizing narrative.

\section{Discussion and implications}

This research had three aims. We first sought to unpack our perspectives of knowledge formation/construction as it relates to quality. Second, we sought to illuminate the dangers of "knowledge capitalism." Finally, we aimed to provide a framework for how researchers and other stakeholders can dismantle barriers to knowledge democracy, thereby revising or challenging perceptions they may have of quality, who reflects it, and who and what dictates what it ought to be.

Our findings outline three themes: framing, saming, and shaming. These themes encompass the seemingly broad assumptions about how knowledge is constructed and narrowly defined. They also perpetuate narrow yet commonly held perspectives of what quality ought to look. We argue that removing blinders will also challenge the perceived need for "vertical partnerships." As suggested by Mwaanga and Adeosun (2017), these one-sided relationships promote the perspective that dominant hegemonic countries need to "think for"and be the "brain" for developing states. 
In this piece, we challenge this assumption. Similar to David Rutkowski (2007), Michael Apple (2000), Gabrielle Russell-Mundine (2012), and Kaz Stuart and Marnee Shay (2018), we question the ethics and sense in promoting homogeneity in education, which often comes at the expense of cultural identity. Our conversations illuminated the dangers of how this practice manifests in academia within the context of research.

\section{Development and theoretical underpinning}

Having developed the framing/saming/shaming mechanism to describe the way perceptions of quality are driven in ECE, we found that through the act of cross-cultural conversations we had named some of the forces driving perceptions of quality. This naming was revelatory for both of us because it brought previously implicit factors into sharp relief and allowed us to recognize obstacles and barriers we had taken for granted or internalized as part of the norms of producing, disseminating, and applying research. An example of this would be Zoyah's use of best-fit but ultimately unsatisfactory scholarship in her own work because of the dearth of nondeficit-lens studies from or about developing nations.

This process of articulating the factors that shape quality served as a transformative dialogue in line with Paulo Freire's (2007) observation that "it is in speaking their word that people, by naming the world, transform it" (p. 45). As such, our cross-cultural conversations have contributed to our critical consciousness in that systems of power which may serve to constrain or suppress were acknowledged and can thus be subverted.

While many have articulated the need to reveal structures and engender agency through dialogue, practical tools for supporting this process are less prevalent. Thus, as action-oriented researchers, we have developed a matrix and associated questions that can be used to engage in a transformative dialogue to develop critical consciousness about the forces that may shape the way research and practice are perceived. The matrix emerged from diagrams we used to describe our experiences of being framed in differing ways in the research space and our frustration at linear models for understanding quality. We present the tool here in the hope that other practitioners and researchers might use it to consider how they perceive their research is positioned in order to navigate, subvert, or challenge entrenched perceptions.

\section{Description of the matrix}

The prominence/perception matrix (P/P matrix) is a highly reflexive tool intended not as a prescriptive and rigid measure but rather a way to consider the ways a country's research output is positioned against others in a manner that makes context a part of this discussion. For example, the Danish forest school is an aspirational discourse (Williams-Siegfredsen, 2012) but is not widely applied. The matrix invites the user to consider their work in relation to that of others and ask questions about the factors which are at work to position research. It resists simple explanations by moving the outputs of knowledge production from a continuum of quality toward more multifaceted explanations. 


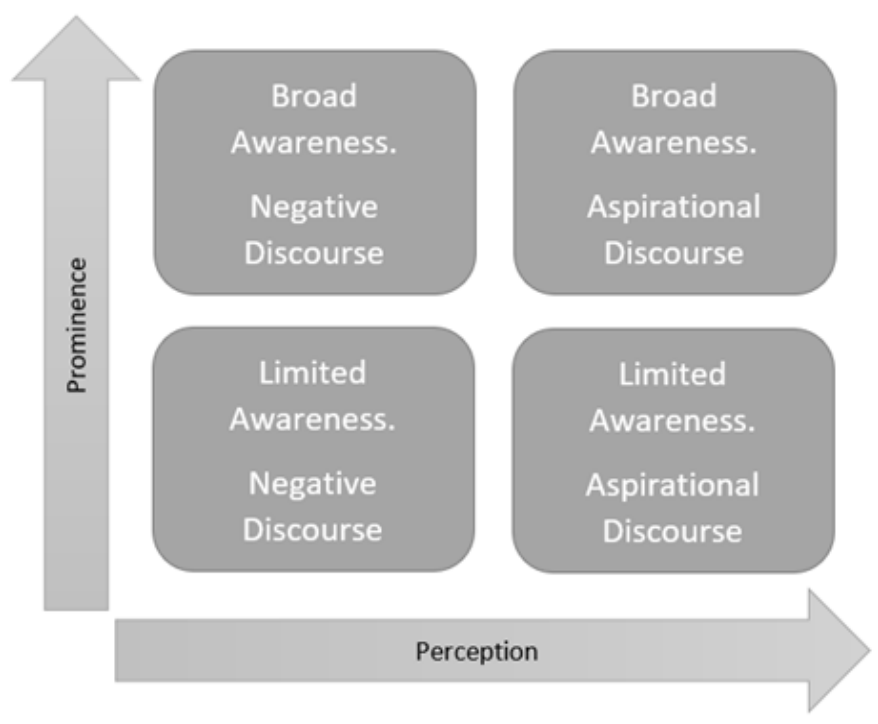

Figure 1: The prominence/perception matrix.

The $\mathrm{x}$ axis of the matrix relates to perceptions of the research or practice in a particular country and moves from negative discourse to inspirational discourse. The y axis relates to the level of prominence the research has and moves from niche to broad. Thus, research outputs can be mapped onto the matrix rather than being considered in a continuum of quality that should only move in one direction. Instead, the matrix offers a useful way to include context in discussions about knowledge production, research, and practice from a range of countries.

\section{Application and utility}

The work the researcher does to position research acts to dismantle barriers by problematizing the factors that place research in one quadrant versus another. For example, the researcher asks questions such as "What factors contribute to an aspirational discourse?" or "What factors contribute to more prominence in the research community?"

The P/P matrix can be used with a set of questions (see Table 3). The first three questions will help the researcher to position their work and the work of otherson the matrix. The second three questions will help the researcher to consider why this positioning is the case. The last three questions are calls to action which will help the researcher subvert or navigate this positioning. We would welcome further research that applies this matrix in practice from both dominant-hegemonic and subordinate positions. 
Table 3. Questions Underpinning the Use of the Prominence/Perception Matrix

\begin{tabular}{|c|c|c|}
\hline $\begin{array}{l}\text { 1. Position the Relevant } \\
\text { Contexts }\end{array}$ & $\begin{array}{l}\text { 2. Evaluate the } \\
\text { Positioning of } \\
\text { Contexts }\end{array}$ & $\begin{array}{l}\text { 3. Address the } \\
\text { Positioning of } \\
\text { Contexts }\end{array}$ \\
\hline $\begin{array}{l}\text { Does research from my } \\
\text { context regularly appear in } \\
\text { journals relevant to my field? }\end{array}$ & $\begin{array}{l}\text { What factors contribute to the } \\
\text { positioning of my context on } \\
\text { the } \mathrm{X} \text { axis of the matrix? }\end{array}$ & $\begin{array}{l}\text { Can I challenge the } \\
\text { positioning of my context in } \\
\text { the research I disseminate? }\end{array}$ \\
\hline $\begin{array}{l}\text { How aspirational is the } \\
\text { practice in my context for } \\
\text { other contexts? }\end{array}$ & $\begin{array}{l}\text { What factors contribute to the } \\
\text { positioning of my context on } \\
\text { the Y axis of the matrix? }\end{array}$ & $\begin{array}{l}\text { Can I apply research from } \\
\text { contexts similar to mine in } \\
\text { order to challenge dominant } \\
\text { discourses? }\end{array}$ \\
\hline $\begin{array}{l}\text { When developing practice and } \\
\text { policy in my context, which } \\
\text { research contexts are held up } \\
\text { as aspirational? }\end{array}$ & $\begin{array}{l}\text { What factors contribute to the } \\
\text { positioning of other contexts } \\
\text { on the matrix? }\end{array}$ & $\begin{array}{l}\text { Can I challenge the status } \\
\text { quo about best practice in my } \\
\text { context at the policy level? }\end{array}$ \\
\hline
\end{tabular}

\section{Conclusion}

It is hoped this study will contribute to the movement seeking to dismantle barriers to knowledge democracy. This hope addresses the driver of framing, which seeks to homogenize perceptions of quality. Using cross-cultural conversations, we drew attention to the dangers of homogenistic beliefs and how they manifest in the spaces in which we exist as researchers. As Brannelly (2016) suggests, the "cultural legacy of colonialism" must be challenged, which would address the perception of quality being driven by saming. Value and knowledge about quality can come from the "formerly colonized" as well as those from the dominant hegemonic position. As two researchers who have made the effort to engage in cross-cultural conversations, we deliberately endeavoured to challenge our current biases and assumptions about quality. This included eschewing the idea that developed countries represent the pinnacle of good practice, considering quality as a process as well as an outcome, and developing a practical tool for engaging in transformative dialogue that rejects the "shaming dialogue" about the forces shaping perceptions of quality. Overall, by uncovering the tacit forces that shape notions of quality, we encourage others to transform how they articulate the drivers that silence practice and research about quality in diverse contexts. 


\section{References}

Alexander, R. J. (2015). Teaching and learning for all? The quality imperative revisited. International Journal of Educational Development,40, 250-258. http://dx.doi.org/10.1016/j.ijedudev.2014.11.012

Apple, M. (2000). Between neoliberalism and neoconservatism: Education and conservatism in a global context. In N. Burbules \& C. Torres (Eds.), Globalization and education: Critical perspectives (pp. 57-78). New York, NY: Routledge.

Beiser, M. (2003). Why should researchers care about culture? Canadian Journal of Psychiatry, 48, 154-160.https://doi.org/10.1177\% 2F070674370304800303

Beliner, W. (2018, January 16). Proposed tests for reception children "verging on the immoral." The Guardian. Retrieved from https:// www.theguardian.com/education/2018/jan/16/tests-reception-children-immoral-england-play

Biesta, G. (2011). Learning democracy in school and society: Education, lifelong learning, and the politics of citizenship. Rotterdam, The Netherlands: Sense.

Boyd, E. (2009). Governing the clean development mechanism: Global rhetoric versus local realities in carbon sequestration projects. Environment and Planning A, 41(10), 2380-2395. https://doi.org/10.1068\%2Fa41341

Brannelly, T. (2016). Decolonising research practices with the ethics of care. Nursing Ethics, 23(1), 4-6. https://doi. org/10.1177\%2F0969733015624297

Braun, V., \& Clarke, V. (2006). Using thematic analysis in psychology. Qualitative Research in Psychology, 3(2), 77-101. http://dx.doi. org/10.1191/1478088706qp063oa

Dua, T., Tomlinson, M., Tablante, E., Britto, P., Yousfzai, A., Daelmans, B., \& Darmstadt, G. L. (2016). Global research priorities to accelerate early child development in the sustainable development era. The Lancet Global Health, 4(12), e887-e889. https://doi. org/10.1016/S2214-109X(16)30218-2

Fredericks, B. L. (2009). The epistemology that maintains white race privilege, power, and control of Indigenous studies and Indigenous peoples' participation in universities. Australian Critical Race and Whiteness Studies Association eJournal, 5(1), 1-12. Retrieved from https://eprints.qut.edu.au/26717/2/26717.pdf

Freire, P. (2007). Pedagogy of the oppressed (M. B. Ramos, Trans.). New York, NY: Continuum. (Original work published 1970)

Gaventa, J., \& Cornwall, A. (2008). Power and knowledge. In P. Reason (Ed.), The SAGE handbook on action research (pp. 172-185). London, UK: SAGE.

Giulianotti, R. (2004). Human rights, globalization, and sentimental education: The case of sport. Sport in Society, 7(3), 355-369. https:// doi.org/10.1080/1743043042000291686

Haigh, N. (2006). Everyday conversation as a context for professional learning and development. International Journal for Academic Development, 10(1), 3-16. https://doi.org/10.1080/13601440500099969

Hall, B. (2014, August 20). No more enclosures: Knowledge democracy and social transformation. Retrieved from https://www.opendemocracy. net/transformation/budd-hall-rajesh-tandon/no-more-enclosures-knowledge-democracy-and-social-transformat

Hall, B., Jackson, T., \& Tandon, R. (2013). Knowledge, democracy, and action: Community university research partnerships in global perspectives. Manchester, UK: Manchester University Press.

Hartmann, D., \& Kwauk, C. (2011). Sport and development. Journal of Sport \& Social Issues, 35(3), 284-305.https://doi. org/10.1177\%2F0193723511416986

Hartung, K. J., \& Wilson, D. G. (2016). Conversational moves that matter. Adult Education Quarterly, 66(3), 254-272. https://doi. org/10.1177\%2F0741713616644778

Ilesanmi, O. O. (2009). What is cross-cultural research? International Journal of Psychological Studies, 1(2), 82-96. http://dx.doi. org/10.5539/ijps.v1n2p82 
Kinkead-Clark, Z. (2015). The role of teacher education in supporting the transformation of early childhood education in Jamaica. Caribbean Educational Research Journal, 3(2), 3-16.

Lewis, J., \& West, A. (2017). Early childhood education and care in England under austerity: Continuity or change in political ideas, policy goals, availability, affordability, and quality in a childcare market? Journal of Social Policy, 46(2), 331-348. https://doi. org/10.1017/S0047279416000647

Lingard, B. (2013). The impact of research on education policy in an era of evidence-based policy. Critical Studies in Education, 54(2), 113-131. https://doi.org/10.1080/17508487.2013.781515

Lloyd, E. (2015). Early childhood education and care policy in England under the coalition government. London Review of Education, 13(2), 144-156. https://doi.org/10.18546/LRE.13.2.12

Moreton-Robinson, A. (2009). Introduction: Critical Indigenous theory. Cultural Studies Review, 15(2), 11-12. https://doi.org/10.5130/ csr.v15i2.2034

Mullett, J. (2015). Issues of equity and empowerment in knowledge democracy: Three community based research examples. Action Research, 13(3), 248-261. https://doi.org/10.1177\%2F1476750315573590

Mwaanga, O., \& Adeosun, K. (2017). Decolonisation in practice: A case study of the Kicking AIDS Out programme in Jamaica. Journal of Sport for Development, 5(9), 58-69. Retrieved from https://www.researchgate.net/publication/323691580_Decolonisation_in_ practice_A_case_study_of_the_Kicking_AIDS_Out_programme_in_Jamaica

National Institute for Health and Care Excellence. (2014). The NICE Way: Lessons for social policy and practice from the National Institute for Health and Care Excellence. London, UK: Alliance for Useful Evidence.

Nesta. (2018). Celebrating five years of the UK What Works Centres. Retrieved from https://www.nesta.org.uk/blog/celebrating-five-yearsof-the-uk-what-works-centres/

Nowell, L., Norris, J., White, D., \& Moules, N. (2017). Thematic analysis: Striving to meet the trustworthiness criteria. International Journal of Qualitative Methods, 16, 1-13. https://doi.org/10.1177\%2F1609406917733847

Openjuru, G., Jaitli, N., Tandon, R., \&Hall, B. (2015). Despite knowledge democracy and community-based participatory action research: Voices from the global south and excluded north still missing. Action Research, 13(3), 219-229. https://doi. org/10.1177\%2F1476750315583316

Pascal, C., et al. (2013). The impact of early education as a strategy in countering socio-economic disadvantage. Centre for Research in Early Childhood. Retrieved from http://www.crec.co.uk/docs/Access.pdf

Rao, N., Sun, J., Wong, J.M.S., Weekes, B., Ip, P., Shaeffer, S. Young, M., Bray, M. Chen, E., \& Lee, D. (2014). Early childhood development and cognitive development in developing countries: A rigorous literature review. Hong Kong: Department for International Development.

Russell-Mundine, G. (2012). Reflexivity in Indigenous research: Reframing and decolonising research? Journal of Hospitality and Tourism Management, 19, 86-90. https://doi.org/10.1017/jht.2012.8

Rutkowski, D. J. (2007). Converging us softly: How intergovernmental organizations promote neoliberal educational policy. Critical Studies in Education, 48(2), 229-247. https://doi.org/10.1080/17508480701494259

Sarna-Wojcicki, D., Perret, M., Eitzel, M. V., \& Fortmann, L. (2017). Where are the missing coauthors? Authorship practices in participatory research. Rural Sociology, 82(4), 713-746. https://doi.org/10.1111/ruso.12156

Schor, N. (1995). Bad objects: Essays popular and unpopular. Durham, NC: Duke University Press.

Schweisfurth, M. (2014). Learner-centred pedagogy: Towards a post-2015 agenda for teaching and learning. International Journal of Educational Development, 40, 259-266. http://dx.doi.org/10.1016/j.ijedudev.2014.10.011

Smith, L. T. (2012). Decolonizing methodologies: Research and Indigenous peoples. Dunedin, New Zealand: Otago University Press. 
Stewart-Brown, S., Anthony, R., Wilson, L., Winstanley, S., Stallard, N., Snooks, H., \& Simkiss, D. (2011). Should randomised controlled trials be the "gold standard" for research on preventive interventions for children? Journal of Children's Services, 6(4), $228-235$. https://doi.org/10.1108/17466661111190929

Stuart, K., \& Shay, M. (2018). Countering epistemological exclusion through critical-ethical research to support social justice: Methodological comparisons between Australia and the United Kingdom. https://doi.org/10.4018/978-1-5225-5317-5.ch009

Suhonen, R., Saarikoski, M., \&Leino-Kilpi, H. (2009). Cross-cultural nursing research. International Journal of Nursing Studies, 46(4), 593-602. https://doi.org/10.1016/j.ijnurstu.2008.09.006

Sullivan, C., \& Cottone, R. (2010). Emergent characteristics of effective cross-cultural research: A review of the literature. Journal of Counseling \& Development, 88(3), 357-362. https://doi.org/10.1002/j.1556-6678.2010.tb00033.x

Tandon, R. (2014). Knowledge democracy: Reclaiming voices for all. New Delhi, India: PRIA.

Timmermans, S., \& Tavory, I. (2012). Theory construction in qualitative research: From grounded theory to abductive analysis. Sociological Theory, 30(3), 167-186. https://doi.org/10.1177\%2F0735275112457914

Tremblay, C., \& de Oliveira Jayme, B. (2015). Community knowledge through participatory video. Action Research, 13(3), $298-314$. https://doi.org/10.1177\%2F1476750315572158

van Widenfelt, B., Treffers, M., Beurs, P., Siebelink, D., \& Koudijs, A. (2005). Translation and cross-cultural adaptation of assessment instruments used in psychological research with children and families. Clinical Child and Family Psychology Review, 8(2), 135147. https://doi.org/10.1007/s10567-005-4752-1

West, A., Roberts, J., \& Noden, P. (2010). Funding early years education and care: Can a mixed economy of providers deliver universal high quality provision? British Journal of Educational Studies, 58(2), 155-179. https://doi.org/10.1080/00071000903520850

Wheeler-Bell, Q. (2017). Standing in need of justification: Michael Apple, R. S. Peters, and Jürgen Habermas. Journal of Curriculum Studies, 49(4), 561-578. https://doi.org/10.1080/00220272.2017.1279219

Williams-Siegfredsen, J. (2012). Understanding the Danish forest school approach. London, UK: Routledge. 